\title{
Front Matter: Volume 7631
}

, "Front Matter: Volume 7631," Proc. SPIE 7631, Optoelectronic Materials and Devices IV, 763101 (31 December 2009); doi: 10.1117/12.853280

EDIE Event: Asia Communications and Photonics, 2009, Shanghai, Shanghai , SPIE. China 


\title{
PROCEEDINGS OF SPIE
}

\section{Optoelectronic Materials and Devices IV}

\author{
Jian-Jun He \\ Guang-Hua Duan \\ Fumio Koyama \\ Ming C. Wu \\ Editors
}

2-6 November 2009

Shanghai, China

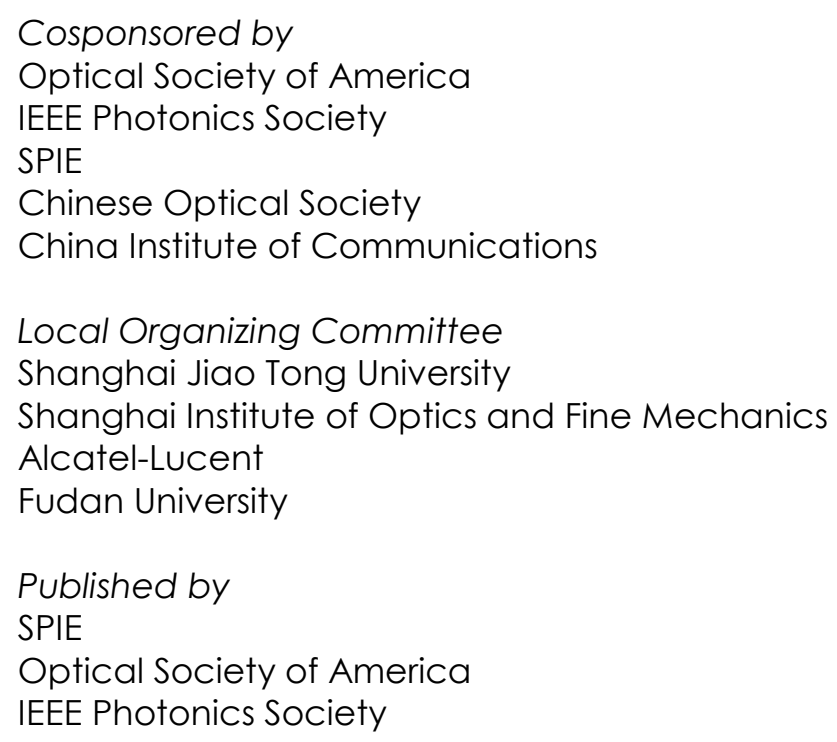


The papers included in this volume were part of the technical conference cited on the cover and title page. Papers were selected and subject to review by the editors and conference program committee. Some conference presentations may not be available for publication. The papers published in these proceedings reflect the work and thoughts of the authors and are published herein as submitted. The publisher is not responsible for the validity of the information or for any outcomes resulting from reliance thereon.

Please use the following format to cite material from this book:

Author(s), "Title of Paper," in Optoelectronic Materials and Devices IV, edited by Jian-Jun He, Guang-Hua Duan, Fumio Koyama, Ming C. Wu, Proceedings of SPIE-OSA-IEEE Asia Communications and Photonics Vol. 7631 (SPIE, Bellingham, WA, 2009) Article CID Number.

ISSN 0277-786X

ISBN 9780819480330

Published by

SPIE

P.O. Box 10, Bellingham, Washington 98227-0010 USA

Telephone +1 3606763290 (Pacific Time) · Fax +1 3606471445

SPIE.org

Optical Society of America

2010 Massachusetts Ave., N.W., Washington, D.C., 20036 USA

Telephone +1 2022238130 (Eastern Time) · Fax +1 2022231096

OSA.org

IEEE Photonics Society

445 Hoes Lane, Piscataway, New Jersey, 08855 USA

Telephone +1 7325628434 (Eastern Time) · Fax +1 7325628434

IEEE.org

Copyright ( ) 2009, Society of Photo-Optical Instrumentation Engineers, Optical Society of America, and IEEE Photonics Society.

Copying of material in this book for internal or personal use, or for the internal or personal use of specific clients, beyond the fair use provisions granted by the U.S. Copyright Law is authorized by SPIE subject to payment of copying fees. The Transactional Reporting Service base fee for this volume is $\$ 18.00$ per article (or portion thereof), which should be paid directly to the Copyright Clearance Center (CCC), 222 Rosewood Drive, Danvers, MA 01923. Payment may also be made electronically through CCC Online at copyright.com. Other copying for republication, resale, advertising or promotion, or any form of systematic or multiple reproduction of any material in this book is prohibited except with permission in writing from the publisher. The CCC fee code is $0277-786 \mathrm{X} / 09 / \$ 18.00$.

Printed in the United States of America.

Publication of record for individual papers is online in the SPIE Digital Library.

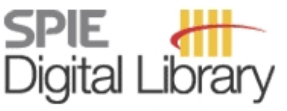

SPIEDigitalLibrary.org

Paper Numbering: Proceedings of SPIE follow an e-First publication model, with papers published first online and then in print and on CD-ROM. Papers are published as they are submitted and meet publication criteria. A unique, consistent, permanent citation identifier (CID) number is assigned to each article at the time of the first publication. Utilization of CIDs allows articles to be fully citable as soon they are published online, and connects the same identifier to all online, print, and electronic versions of the publication. SPIE uses a six-digit CID article numbering system in which:

- The first four digits correspond to the SPIE volume number.

- The last two digits indicate publication order within the volume using a Base 36 numbering system

employing both numerals and letters. These two-number sets start with 00, 01, 02, 03, 04, 05, 06, 07, 08, 09, 0A, $\mathrm{OB}$... OZ, followed by $10-1 \mathrm{Z}, 20-2 \mathrm{Z}$, etc.

The CID number appears on each page of the manuscript. The complete citation is used on the first page, and an abbreviated version on subsequent pages. Numbers in the index correspond to the last two digits of the six-digit CID number. 


\section{Contents}

xiii Organizing Committee

$\mathrm{xv}$ Conference Committee

\section{VCSELS}

763102 Fabrication and characterization of 1.3- $\mu \mathrm{m}$ InAs quantum-dot VCSELS and monolithic VCSEL arrays [7631-75]

Y. Ding, W. J. Fan, D. W. XU, Nanyang Technological Univ. (Singapore); L. J. Zhao, Y. Liu, N. H. Zhu, Institute of Semiconductors (China)

\section{BEST STUDENT PAPER SESSION}

763103 Experimental demonstration of an ultracompact polarization beam splitter based on a bidirectional grating coupler (Best Student Paper Award) [7631-37]

Z. Wang, Y. Tang, N. Zhu, L. Wosinski, Royal Institute of Technology (Sweden) and JORCEP, Zhejiang Univ. (China); D. Dai, JORCEP, Zhejiang Univ. (China); U. Westergren, S. He, Royal Institute of Technology (Sweden) and JORCEP, Zhejiang Univ. (China)

763104 Monolithically integrated 30-wavelength DFB laser array [7631-65]

J. Li, X. Chen, Nanjing Univ. (China); N. Zhou, Accelink Technologies Co., Ltd. (China); J. Zhang, Chongqing Optoelectronics Research Institute (China); X. Huang, L. Li, Accelink Technologies Co., Ltd. (China); H. Wang, Institute of Semiconductors (China); Y. Lu, Nanjing Univ. (China); H. Zhu, Institute of Semiconductors (China)

763105 Silicon-chip-based frequency quadrupling for optical millimeter-wave signal generation [7631-36]

F. Liu, T. Wang, L. Zhang, Shanghai Jiao Tong Univ. (China); J. Wang, M. Qiu, Royal Institute of Technology (Sweden); Y. Su, Shanghai Jiao Tong Univ. (China)

\section{OPTICAL MEMS AND VERTICAL CAVITY TUNABLE DEVICES}

763106 Properties of wavelength tunable VCSELs with MEMS cantilever [7631-78]

B. Guan, X. Guo, J. Deng, G. Shen, Beijing Univ. of Technology (China)

763107 Investigation on tunable wavelength and modal characteristics of MEMS tunable vertical cavity surface emitting lasers [7631-53]

J. Zhang, X. Guo, B. Guan, D. Chuai, G. Shen, Beijing Univ. of Technology (China)

763108 Design and fabrication of multichannel tunable photodetector array [7631-25]

X. Duan, Y. Huang, X. Ren, H. Huang, Q. Wang, S. Wang, Y. Shang, X. Ye, S. Cai, Beijing Univ. of Posts and Telecommunications (China) 
763109 Optical switch based on nanocrystalline VO ${ }_{x}$ thin film [7631-01]

X. Chen, Wuhan Polytechnic Univ. (China); J. Dai, Huazhong Univ. of Science and

Technology (China) and Wuhan National Lab. for Optoelectronics (China)

\section{PLANAR WAVEGUIDE DEVICES}

7631 OA Novel approach for planar Bragg grating characterization using prism coupling [7631-94] J. Pello, Nanyang Technological Univ. (Singapore) and Thales Technology Ctr. (Singapore); T. Le, A. Lim, Nanyang Technological Univ. (Singapore); E. Dogheche, IEMN, CNRS, Univ. de Valenciennes (France); M. Kaba, Nanyang Technological Univ. (Singapore) and Thales Technology Ctr. (Singapore); K. Pita, Nanyang Technological Univ. (Singapore); D. Decoster, IEMN, CNRS, Univ. de Valenciennes (France); J.-P. Huignard, Thales Research and Technology (France); S. C. Tjin, Nanyang Technological Univ. (Singapore) and Thales Technology Ctr. (Singapore); J. Chazelas, Thales Technology Ctr. (Singapore) and Thales Systemes Aeroportes (France)

$7631 \mathrm{OB}$ Observation of the thermal nonlinear optical effect in a microring resonator based on a small SU-8 polymer ridge optical waveguide [7631-45]

L. Yang, D. Dai, J. He, S. He, Zhejiang Univ. (China)

7631 OC Enhancement of the evanescent coupling between III-V/Si hybrid microring laser and bus waveguide by using a bending coupler [7631-72]

D. Dai, Univ. of California, Santa Barbara (United States) and Zhejiang Univ. (China);

D. Liang, J. E. Bowers, Univ. of California, Santa Barbara (United States)

\section{ALL-OPTICAL SIGNAL PROCESSING}

7631 OD Simultaneous demonstration on FWM-based all-optical 40 Gbit/s multicasting CSRZ-DPSK logic XOR gate and CSRZ-DPSK to RZ-DPSK format conversion [7631-122]

J. Wang, Huazhong Univ. of Science and Technology (China) and Univ. Of Southern California, Los Angeles (United States); Q. Sun, J. Sun, Huazhong Univ. of Science and Technology (China)

7631 OE All-optical clock recovery for 40Gbs using an amplified feedback DFB laser [7631-112] Y. Sun, J. Q. Pan, L. J. Zhao, W. X. Chen, W. Wang, Institute of Semiconductors (China); L. Wang, X. F. Zhao, C. Y. Lou, Tsinghua Univ. (China)

7631 OF A novel all-optical clock recovery scheme [7631-76] F. Wang, Huazhong Univ. of Science and Technology (China) and Chongqing Institute of Technology (China); X. Zhang, E. XU, Y. Zhang, Huazhong Univ. of Science and Technology (China)

$76310 \mathrm{G} \quad 40 \mathrm{~Gb} / \mathrm{s}$ all-optical format conversion from NRZ to PolSK using a single SOA assisted by optical bandpass filter [7631-39]

P. Li, Nanjing Univ. of Posts \& Telecommunications (China); D. Huang, Huazhong Univ. of Science and Technology (China) 
7631 ol Specialty high bandwidth multimode fiber for optical interconnection (Invited Paper) [7631-111]

Y. Sun, R. Lingle, Jr., D. Mazzarese, D. S. Vaidya, X. Jiang, OFS Fitel, LLC (United States); M. Yan, OFS Labs. (United States); G. Oulundsen, J. Kim, J. Kamino, K. Bradley, OFS Fitel, LLC (United States)

7631 0J Study on high-speed photodetectors with plasmonics filter [7631-113] Y. Shang, Y. Huang, X. Duan, X. Ye, H. Huang, S. Cai, Q. Wang, X. Ren, Beijing Univ. of Posts and Telecommunications (China)

\section{PHOTONIC INTEGRATION}

7631 OK Design of complex semiconductor integrated structures [7631-106]

C. Arellano, VPIsystems (Germany); S. Mingaleev, A. Novitsky, VPI Development Ctr. (Belarus); I. Koltchanov, A. Richter, VPIsystems (Germany)

MID-INFARED AND THZ DEVICES

7631 OL Dual-color mid-infrared quantum cascade photodetector in coupled quantum well structure [7631-59]

A. Rostami, Univ. of Tabriz (Iran, Islamic Republic of); A. Motmaen, Islamic Azad Univ. Tabriz Branch (Iran, Islamic Republic of); H. Baghban, H. Rasooli Saghai, Univ. of Tabriz (Iran, Islamic Republic of)

$76310 \mathrm{M}$ Fiber-based THz sources based on monolithic single-frequency pulsed fiber lasers in the C-band [7631-47]

W. Shi, NP Photonics, Inc. (United States); E. B. Petersen, J. Meair, NP Photonics, Inc. (United States) and The Univ. of Arizona (United States); D. T. Nguyen, J. Zong, Z. Yao,

A. Chavez-Pirson, NP Photonics, Inc. (United States); N. Peyghambarian, NP Photonics, Inc. (United States) and College of Optical Sciences, The Univ. of Arizona (United States)

$76310 \mathrm{~N}$ Two-wavelength THz quantum cascade laser with highly enhanced temperature characteristics [7631-58]

A. Rostami, B. Mirzaei, H. Babhban, Univ. of Tabriz (Iran, Islamic Republic of)

763100 Research on dielectric properties of gallium arsenides by using THz-TDS [7631-204] J. Li, X. Zhao, J. Li, China Jiliang Univ. (China)

\section{SILICON PHOTONICS}

7631 OP Low-power electro-optical switch based on a III-V microdisk cavity on a silicon-on-insulator circuit [7631-62]

L. Liu, IMEC, Univ. Gent (Belgium) and Technical Univ. of Denmark (Denmark); G. Roelkens, T. Spuesens, IMEC, Univ. Gent (Belgium); R. Soref, Air Force Research Lab. (United States);

P. Regreny, Institut des Nanotechnologies de Lyon, CNRS, Univ. de Lyon (France);

D. Van Thourhout, R. Baets, IMEC, Univ. Gent (Belgium) 
$76310 Q \quad$ A compact electrically-pumped hybrid silicon microring laser [7631-07]

D. Liang, T. Okumura, H.-H. Chang, D. Spencer, Y.-H. Kuo, A. W. Fang, D. Dai, Univ. of California, Santa Barbara (United States); M. Fiorentino, R. G. Beausoleil, Hewlett-Packard Labs. (United States); J. E. Bowers, Univ. of California, Santa Barbara (United States)

7631 OR Photoluminescence with ultra-wide spectrum from radiative defects in Si-rich SiN $_{\mathbf{x}}$ [7631-55] W. Ke, X. Feng, X. Tang, Tsinghua Univ. (China); Y. Tanaka, D. Ohnishi, ROHM Co., Ltd. (Japan); Y. Huang, Tsinghua Univ. (China)

\section{FABRICATION TECHNOLOGIES}

7631 OS A study on the $\mathrm{Cl}_{2} / \mathrm{C}_{2} \mathrm{H}_{4}$ /Ar plasma etching of ITO using inductively coupled plasma [7631-06]

R. Fang, W. J. Jiang, X. Guo, J. R. Han, G. D. Shen, Beijing Univ. of Technology (China)

7631 OT Point defects in relaxed and strained Si studied by molecular dynamics method [7631-68] Z. Chen, Z. YU, P. LU, Y. Liu, Beijing Univ. of Posts and Telecommunications (China)

7631 OU Effect of fabrication parameters on luminescent properties of ZnS:Mn nanocrystals [7631-108]

S. Shaari, M. S. A. Rahman, N. A. A. M. Arif, Univ. Kebangsaan Malaysia (Malaysia)

\section{NONLINEAR OPTICS}

$76310 \mathrm{~V}$ Study on third-order nonlinear optical properties of $\left[\left(\mathrm{C}_{4} \mathrm{H}_{9}\right)_{4} \mathrm{~N}\right] \mathrm{Au}(\mathrm{dmit}){ }_{2}$ using Z-scan technique [7631-60]

H. Yang, W. Ji, Q. Ren, X. Wang, F. Zhang, Shandong Univ. (China)

7631 OW Linear and nonlinear optical properties of an organic polymer composite film [7631-114] Q. Sun, Q. Ren, X. Wang, Shandong Univ. (China); T. Li, Taishan Univ. (China); H. Yang, F. Zhang, J. Chen, Shandong Univ. (China)

$76310 X \quad$ Experimental investigations on transverse spatial profile of beam in an SBS generator [7631-104]

H. Gong, Y. Jin, China Jiliang Univ. (China); D. Lin, Harbin Institute of Technology (China)

7631 OY Measurement of the carrier recovery time in SOA based on dual pump FWM [7631-79] C. Cheng, X. Zhang, Y. Zhang, L. Liu, E. Zhou, D. Huang, Huazhong Univ. of Science and Technology (China)

$76310 Z$ Mathematical modeling and statistical analysis of SPE-OCDMA systems utilizing second harmonic generation effect in thick crystal receivers [7631-99]

M. D. Matinfar, J. A. Salehi, Sharif Univ. of Technology (Iran, Islamic Republic of)

763110 Temperature investigation of frequency upconversion in $\mathrm{Er}^{3+} / \mathrm{Yb}^{3+}$-codoped PLZT electro-optic ceramic [7631-32]

Z. Feng, L. Lin, K. Shi, J. Lin, G. Zhuang, Z. Zheng, Fujian Normal Univ. (China) 
763111 Optical pulses compression using time lens [7631-50]

Z. Tan, N. Zhou, M. Chen, T. Gong, W. Ren, P. Tao, Y. Chang, S. Jian, Beijing Jiaotong Univ. (China)

763112 Soliton compression of femtosecond pulses in two-segment quasi-phase-matching grating [7631-201]

X. Zeng, Z. Wang, T. Wang, Shanghai Univ. (China)

763113 Doping profile effect on picosecond lasing of an internally Q-switched, high-power laser diode [7631-38]

B. Lanz, S. Vainshtein, J. Kostamovaara, Univ. of Oulu (Finland); V. Lantratov, N. Kalyuzhnyy, loffe Physical-Technical Institute (Russian Federation)

763114 High-power ultra-short pulse UV laser system [7631-49]

J. Chen, J.-C. Chen, S.-Y. Lin, C.-H. Yeh, C.-Y. Liu, Chung-Hua Univ. (Taiwan, China)

\section{HIGH-SPEED DEVICES}

763115 40G and 100G modules enable next generation networks (Invited Paper) [7631-98] J. Hong, T. Schmidt, M. Traverso, Opnext, Inc. (United States); E. Yoshikazu, Opnext Japan, Inc. (Japan)

763116 Advanced InP technology for high-performance 40 Gb/s (RZ-) DQPSK transponder [7631-102]

J. Mo, Oclaro Technology (Shenzhen) Co., Ltd. (China); R. Griffin, T. Goodall, Oclaro Technology plc (United Kingdom); Z. He, Oclaro Technology (Shenzen) Co., Ltd. (China)

763117 40Gb/s DPSK receiver module for $C+L$ band with athermal free-space delay-line-interferometer [7631-117]

A. G. Steffan, M. L. Nielsen, A. Umbach, U² Photonics AG (Germany); A. Boutin, L. Fulop, F. Verluise, Kylia (France)

763118 Analysis of key methods of MZ setup in TTA [7631-63] M. Wang, Y. Xu, Oclaro Technology (Shenzhen) Co., Ltd. (China); S. Gardner, Oclaro Technology plc (United Kingdom)

763119 High data rate 850-nm oxide VCSEL for 20 Gbit/s application and beyond [7631-121] C. Ji, J. Wang, D. Söderström, L. Giovane, Avago Technologies Ltd. (United States)

7631 1A Energy level properties of coupled quantum well and the optimal design for traveling-wave modulators [7631-52]

Z. Xu, Zhejiang Univ. of Science and Technology (China) 


\section{NANOPHOTONICS}

7631 1C A 1550nm PbSe quantum dots fiber amplifier excited by evanescent wave [7631-200] J. Wang, F. Pang, X. Zeng, Z. Chen, T. Wang, Shanghai Univ. (China)

7631 ID Enhanced spontaneous emission of electric dipole by nano-optical antenna [7631-74] H. Gao, K. Li, F. M. Kong, H. Xie, J. Zhao, Shandong Univ. (China)

$7631 \mathrm{lE} \quad$ Yb-doped silica preform precursor nanoparticles and the photodarkening in them [7631-116]

L. Xiong, E. H. Sekiya, K. Saito, Toyota Technological Institute (Japan)

\section{MAGNETO-OPTICS AND ACOUSTO-OPTICS}

7631 IF RF-sputtered Bi-substituted iron garnet composite films for visible-range magneto-optics [7631-13]

M. Nur-E-Alam, M. Vasiliev, K. Alameh, Edith Cowan Univ. (Australia); V. A. Kotov, Institute of Radio Engineering and Electronics (Russian Federation)

7631 1G A novel magneto-optic switch based on nanosecond pulse [7631-19] Q. Wu, Changzhou College of Information Technology (China); J. Ruan, Z. Weng, S. Lin, Xiamen Univ. (China)

\section{SEMICONDUCTOR LASERS I}

7631 1J Quantum dot micropillar lasers (Invited Paper) [7631-203]

S. Reitzenstein, C. Kistner, S. Münch, T. Heindel, C. Schneider, M. StrauB, A. Rahimi-Iman, K. Morgener, S. Höfling, M. Kamp, A. Forchel, Julius-Maximilians-Univ. Würzburg (Germany)

7631 1K A widely tunable ridge width varied two-section partly gain-coupled DFB self-pulsation laser for optical microwave generation [7631-08]

D. Kong, H. Zhu, S. Liang, Institute of Semiconductors (China); X. Zhao, L. Wang, Tsinghua Univ. (China); B. Wang, L. Zhao, Institute of Semiconductors (China)

\section{PHOTODETECTORS}

7631 IL Silicon-based long wavelength photodetectors (Invited Paper) [7631-92]

B. Cheng, H. Xue, C. Xue, C. Li, C. Li, W. Hu, Y. ZuO, Q. Wang, Institute of Semiconductors (China)

$76311 \mathrm{M}$ Study on high-speed photodetectors with plasmonics flilter [7631-61] Y. Shang, Y. Huang, X. Duan, X. Ye, H. Huang, S. Cai, Q. Wang, X. Ren, Beijing Univ. of Posts and Telecommunications (China)

7631 1N DESIGN subwavelength gratings in resonant cavity enhanced (RCE) photodetectors [7631-15] Y. Yang, Y. Huang, H. Huang, Q. Wang, X. Ren, Beijing Univ. of Posts and Telecommunications (China) 
763110 RCE photodetector with cascaded grating structure [7631-09]

X. Zhang, Y. Huang, X. Ren, H. Huang, Q. Wang, Beijing Univ. of Posts and

Telecommunications (China)

7631 1P Low cost camera modules using integration of wafer-scale optics and wafer-level packaging of image sensors [7631-105]

H. Han, K. Main, Tessera North America (United States)

\section{SEMICONDUCTOR LASERS II}

7631 1Q AlGalnAs quantum-well lasers with semi-insulating buried-heterostructure for high-speed direct modulation up to $\mathbf{4 0}$ Gbps (Invited Paper) [7631-46]

K. Otsubo, M. Matsuda, Fujitsu Labs., Ltd. (Japan), Fujitsu Ltd. (Japan), and Optoelectronic Industry and Technology Development Association (Japan); K. Takada, S. Okumura, Fujitsu Labs., Ltd. (Japan); A. Uetake, M. Ekawa, T. Yamamoto, Fujitsu Labs., Ltd. (Japan), Fujitsu Ltd. (Japan), and Optoelectronic Industry and Technology Development Association (Japan)

7631 IR Laser diode comb spectrum amplification preserving low RIN for WDM applications [7631-89]

D. Yin, Innolume, Inc. (United States); A. Gubenko, I. Krestnikov, D. Livshits, S. Mikhrin, Innolume GmbH (Germany); A. Kovsh, G. Wojcik, Innolume, Inc. (United States)

7631 is High power cooled mini-DIL pump lasers [7631-34]

B. Liang, Oclaro Technology (Shenzhen) Co., Ltd. (China); N. Zayer, Oclaro Technology plc (United Kingdom); B. Chen, D. He, Oclaro Technology (Shenzhen) Co., Ltd. (China); T. Pliska, Oclaro (Switzerland) AG (Switzerland)

\section{PHOTONIC CRYSTALS I}

7631 IU Novel analytical band-gap analysis of rectangular photonic crystals [7631-26]

X. Guo, Z. YU, Y. Liu, L. Zhao, D. Wang, Beijing Univ. of Posts and Telecommunications (China)

7631 1V A special kind of photonic crystal and enlargement of omnidirectional total reflection band [7631-83]

H. Qiang, W. Jia, L. Jiang, X. Li, Nanjing Univ. of Science and Technology (China)

7631 IW Analysis of mode characteristic for square resonators with a hole at the center [7631-67] S.-J. Wang, Y.-Z. Huang, Y.-D. Yang, J.-L. Xiao, Institute of Semiconductors (China)

\section{QUANTUM DOT MATERIALS AND DEVICES}

7631 1X SPICE equivalent circuit model of quantum-dot semiconductor optical amplifiers [7631-57] A. Rostami, R. Maram Q, H. Baghban, H. Rasooli S., R. Ghorbani, Univ. of Tabriz (Iran, Islamic Republic of)

7631 iY Electronic structure of quantum dots in (111) direction [7631-44]

W. Zhao, Z. Yu, Y. Liu, Beijing Univ. of Posts and Telecommunications (China) 
7631 1Z Calculation of exciton energy in InAs/InP self-assembled semiconductor quantum wires [7631-64]

Z. XU, Y. Liu, Z. Yu, W. Yao, Beijing Univ. of Posts and Telecommunications (China)

763120 Degenerate two-wave mixing based energy transfer and phase modulation in colloid CdSe quantum dots [7631-96]

Q. Yang, J. Seo, B. Tabibi, Hampton Univ. (United States); W. Yu, Worcester Polytechnic Institute (United States)

$763121 \quad$ Pump controllable optical delay line using CdSe quantum dots [7631-95]

Q. Yang, J. Seo, B. Tabibi, Hampton Univ. (United States); W. YU, Worcester Polytechnic Institute (United States)

\section{PHOTONIC CRYSTALS II}

763122 Optical channel drop filters based on $45^{\circ}$ photonic crystal ring resonators [7631-17] J. Bai, J. Wang, B. Ni, J. Jiang, Fujian Normal Univ. (China); X. Chen, Minjiang Univ. (China); Y. Qiu, Z. Qiang, Fujian Normal Univ. (China)

763123 New design of a triplexer using ring resonator integrated with directional coupler based on photonic crystals [7631-30]

Y.-D. Wu, T.-T. Shih, J.-J. Lee, National Kaohsiung Univ. of Applied Sciences (China)

763124 A new method for optimization of a photonic crystal waveguide termination [7631-31]

D. Wang, Z. Yu, Y. Liu, P. Lu, Beijing Univ. of Posts and Telecommunications (China)

763125 Fabrication of the amendatory one-dimensional photonic crystals for SHF reflector antennas [7631-133]

B. Li, S. Huang, Beijing Univ. of Posts and Telecommunications (China); K.-J. Lee, Oriental Institute of Technology (Taiwan, China); H.-T. Chou, Yuan Ze Univ. (Taiwan, China); W. Gu, Beijing Univ. of Posts and Telecommunications (China)

763126 Decoupling efficiency of multiple coupled photonic crystal waveguides [7631-202]

T. YU, Nanchang Univ. (China) and Institute of Semiconductors (China); L. He, J. Zhang,

L. Fang, P. Wu, Nanchang Univ. (China)

763127 Fabry-Perot interferometer in a rod-type photonic crystal based on self-collimation [7631-40]

G. Lin, X. Chen, N. Lin, H. Lin, Minjiang Univ. (China); Y. Wang, Longyan Univ. (China); J. Bai,

J. Li, Z. Qiang, Y. Qiu, Fujian Normal Univ. (China)

\section{POSTER SESSION}

763128 Highly compact organic electro-optic modulator based on nanoscale plasmon metal gap waveguides [7631-82]

S. Inove, S. Yokoyama, Kyushu Univ. (Japan)

763129 Reflective planar microcavity with enhanced electro-optic activity of a poled polymer [7631-84]

A. Inove, S. Inoue, S. Yokoyama, Kyushu Univ. (Japan) 
7631 2A InP nanowires with various morphologies formed by Au-assisted metal-organic chemical vapor deposition [7631-91]

H. Huang, X. Ren, X. Ye, J. Guo, Y. Yang, Q. Wang, Y. Huang, Beijing Univ. of Posts and

Telecommunications (China)

7631 2B The formation of optical waveguide in KTP crystal by combining ion implantation with ion exchange [7631-71]

X. Ming, F. Lu, X. Wang, M. Chen, Shandong Univ. (China); X. Liu, Shandong Univ. (China) and Institute of Automation (China)

7631 2C Large separating angle multiway beam splitter based on photonic crystal ring resonators [7631-29]

P. Hu, H. Guo, Q. Liao, Nanchang Univ. (China)

$76312 \mathrm{D}$ Growth of GaAs nanowires with various thickness of Au film [7631-86]

X. Ye, H. Huang, X. Ren, Y. Yang, S. Cai, Y. Huang, Q. Wang, Beijing Univ. of Posts and Telecommunications (China)

$76312 \mathrm{E} \quad$ Ultra-broadband dispersion measurement of photonic crystal fiber based on supercontinuum pulses [7631-10]

X. Liu, Z. Wang, J. Hou, D. Liang, A. Jin, National Univ. of Defense Technology (China)

$76312 \mathrm{~F}$ Surface-plasmons enhanced light emitter based on Ag film in GaN [7631-81]

J. Zhao, K. Li, F. M. Kong, L. G. Du, Y. Z. Lin, H. Gao, Shandong Univ. (China)

$76312 \mathrm{G}$ Photoluminescence properties of Nd-O+-codoped Si-based thin film [7631-24]

M. Yuan, C. Li, X. Leng, Q. Wang, Nanchang Univ. (China)

$76312 \mathrm{H}$ Thermal annealing effect on the Mg-doped AIGaN/GaN superlattice [7631-90] B. Wang, Hebei Univ. of Science and Technology (China) and Institute of Semiconductors (China); S. An, H. Wen, R. Wu, X. Wang, Hebei Univ. of Science and Technology (China);

$X$. Wang, Institute of Semiconductors (China)

$763121 \quad$ Low-temperature Si/Si wafer bonding using boride-treated surface [7631-42] H. Song, H. Huang, X. Ren, W. Wang, Y. Huang, Beijing Univ. of Posts and Telecommunications (China)

$76312 \mathrm{~J} \quad$ An ultra-short 1x2 double-wavelength optical power splitter for 1310/1550-nm operation based on photonic crystal multimode interference [7631-28]

W. Li, Nanchang Engineering Institute College (China); X. Xu, Nanchang Univ. (China); Y. He, Nanchang Engineering Institute College (China); L. Tao, Nanchang Univ. (China)

7631 2K A novel dual-absorption resonant cavity enhanced photodetectors [7631-18] P. Fu, Y. Huang, X. Duan, X. Ren, H. Huang, Q. Wang, Beijing Univ. of Posts and Telecommunications (China)

$76312 \mathrm{~L} \quad$ Coupling characteristics of electromagnetic waves in ultra-short parallel between four photonic crystal waveguides and its application [7631-12]

$X . X U$, Nanchang Univ. (China); W. Li, Nanchang Engineering Institute College (China);

L. Tao, Nanchang Univ. (China) 
7631 2M Electronic dispersion compensation for PMD in 40-GB/s optical links [7631-02]

K. Yang, J. Liu, X. Zeng, Hebei Univ. of Technology (China)

$76312 \mathrm{~N}$ Analysis of the dynamics of frequency upconversion in $\mathrm{Er}^{3+} / \mathrm{Yb}^{3+}$ co-doped $\mathrm{KY}\left(\mathrm{WO}_{4}\right)_{2}$ crystal [7631-33]

J. Lin, Z. Feng, L. Lin, K. Shi, Z. Zheng, Fujian Normal Univ. (China)

763120 Synthesis and photoelectrical properties of zinc phthalocyanine-bisphenol A epoxy derivative [7631-41]

W. Cheng, Y. Shen, F. Zheng, F. GU, J. Zhang, Shanghai Univ. (China)

$76312 \mathrm{P}$ Optical characteristic of cotton in the THz frequency region [7631-51]

J. Li, J. Li, China Jiliang Univ. (China)

$76312 Q$ The electrical properties of the diamond field effect transistor [7631-123]

Y. Zhang, L. Wang, J. Huang, K. Tang, F. Zhang, Q. Fang, Q. Zeng, R. XU, J. Zhang, J. Min,

Y. Xia, Shanghai Univ. (China)

$76312 R \quad$ Theoretical and experimental research of lens duct as coupling system for LDA [7631-93]

X. Liu, S. Fu, Shandong Univ. of Technology (China)

Author Index 


\title{
Organizing Committee
}

\author{
Honorary General Chairs
}

Guofan Jin, Tsinghua University (China)

Hequan Wu, Chinese Academy of Engineering (China)

Jie Zhang, Jiao Tong University (China)

Bingkun Zhou, Chinese Optical Society (China)

General Chairs

Kwok-Wai Cheung, The Chinese University of Hong Kong (Hong Kong, China)

Sailing He, Joint Research Center of the Royal Institute of Technology (Sweden) and Zhejiang University (China)

John Zyskind, JDSU Uniphase Corporation (United States)

Technical Program Chairs

Weisheng Hu, Shanghai Jiao Tong University (China)

Ming-Jun Li, Corning, Inc., (United States)

Dennis Matthews, University of California, Davis (United States)

Local Organizing Committee Chair

Yaohui Jin, Shanghai Jiao Tong University (China)

Local Organizing Committee

Nan Chi, Fudan University (China)

Weisheng Hu, Shanghai Jiao Tong University (China)

Feng Huang, Alcatel-Lucent Shanghai Bell (China)

Ronghui Qu, Institute for Optics and Fine Mechanics (China)

Weiqiang Sun, Shanghai Jiao Tong University (China) 
Downloaded From: https://www.spiedigitallibrary.org/conference-proceedings-of-spie on 26 Apr 2023

Terms of Use: https://www.spiedigitallibrary.org/terms-of-use 


\title{
Conference Committee
}

\author{
Conference Chair
}

Jian-Jun He, Zhejiang University (China)

Conference Cochairs

Guang-Hua Duan, Alcatel-Thales III-V Laboratory (France)

Fumio Koyama, Tokyo Institute of Technology (Japan)

Ming C. Wu, University of California, Berkeley (United States)

Program Committee

Markus C. Amann, Technische Universität München (Germany)

Yong-Zhen Huang, Institute of Semiconductors, CAS (China)

Wei-Ping Huang, McMaster University (Canada)

Yongzhen Huang, Institute of Semiconductors, CAS (China)

Shan Jiang, Accelink Technologies Company Ltd. (China)

Akihiko Kasukawa, Furukawa Electric Company Ltd. (Japan)

Yong-Hee Lee, Korea Advanced Institute of Science and Technology

(Korea, Republic of)

Christian Lerminiaux, Université de Technologie de Troyes (France)

Lih Y. Lin, University of Washington (United States)

Shinji Matsuo, NTT Photonics Laboratories, NTT Corporation (Japan)

Ting Mei, Nanyang Technological University (Singapore)

Haisheng Rong, Intel Corporation (United States)

Junqiang Sun, Huazhong University of Science and Technology

(China)

Valery Tolstikhin, OneChip Photonics Inc. (Canada)

Shinji Tsuji, Hitachi Central Research Laboratories (Japan)

Dries Van Thourhout, Ghent University, IMEC (Belgium)

Sy Wang, HP Laboratories (United States)

Liming Zhang, Bell Laboratories, Alcatel-Lucent (United States)

Zhiping Zhou, Peking University (China)

Session Chairs

$1 \quad$ VCSELS

Tim Lu, National Chiao Tung University (Taiwan, China)

2 Best Student Paper Session

Jian-Jun He, Zhejiang University (China) 
3 Optical MEMS and Vertical Cavity Tunable Devices

Jin Hong, Opnext, Inc. (United States)

$4 \quad$ Planar Waveguide Devices

Chenglin Xu, RSoft Design Group, Inc. (United States)

5 Special Session on Optical Interconnect for Green ICT I

Akihiko Kasukawa, The Furukawa Electric Company Ltd. (Japan)

$6 \quad$ All-Optical Signal Processing

Wei Li, University of Wisconsin-Platteville (United States)

7 Special Session on Optical Interconnect for Green ICT II

Akihiko Kasukawa, The Furukawa Electric Company Ltd. (Japan)

8 Photonic Integration

Valery I. Tolstikhin, OneChip Photonics Inc. (Canada)

9 Mid-Infared and $\mathrm{THz}$ Devices

Wei Li, University of Wisconsin-Platteville (United States)

11 Silicon Photonics

Zhiping Zhou, Peking University (China)

12 Fabrication Technologies

Buwen Cheng, Institute of Semiconductors, CAS (China)

12 Nonlinear Optics

Junqiang Sun, Huazhong University of Science and Technology (China)

13 Ultra-Short Optical Pulses

Katsunari Okamoto, AiDi Corporation (Japan)

14 Plasmonic Nanostructures

Christian Lerminiaux, Université de Technologie Troyes (France)

15 High-Speed Devices

Koji Otsubo, Fujitsu Laboratories, Ltd. (Japan)

16 Nanophotonics

Fumio Koyama, Sr. Tokyo Institute of Technology (Japan)

17 Magneto-optics and Acousto-optics

Yi Sun, OFS Fitel, LLC (United States)

18 Semiconductor Lasers I

Liming Zhang, Bell Laboratories, Alcatel-Lucent (United States) 
19 Photodetectors

Buwen Cheng, Institute of Semiconductors, CAS (China)

20 Semiconductor Lasers II

Guang-Hua Duan, Alcatel-Thales III-V Laboratory (France)

21 Photonic Crystals I

Younan Xia, Washington University in St. Lovis (United States)

22 Quantum Dot Materials and Devices

Stephan Reitzenstein, Julius-Maximilians-Universität Würzburg (Germany)

23 Photonic Crystals II

Min Qiu, Royal Institute of Technology (Sweden) 
Downloaded From: https://www.spiedigitallibrary.org/conference-proceedings-of-spie on 26 Apr 2023

Terms of Use: https://www.spiedigitallibrary.org/terms-of-use 